Vol. 2, No. 2, pp. 117-124, 2021

\title{
Numerical Integration Implementation Using Trapezoidal Rule Method to Calculate Aproximation Area of West Java Province
}

\author{
Wida Nurul Fauziyah*, Athaya Zahrani Irmansyah, Sri Purwani \\ Department of Mathematics, Faculty of Mathematics and Natural Sciences, \\ Universitas Padjadjaran, Jl. Raya Bandung-Sumedang KM 21, Jatinangor, Sumedang, Jawa Barat, 45363 \\ *Corresponding author e-mail: wida2001@mail.unpad.ac.id
}

\begin{abstract}
An area can be shaped into a regular shape or an irregular shape. There is an area of irregular shape which is restricted by an unknown function, to determine that area must use a numerical integration. One of numerical integration methods is Trapezoidal Rule by replacing $(x)$ with an integral approach function which can be evaluated, then let the $(x)$ approximated by a linear polynomial in the certain interval, denoted as closed interval $[a, b]$. This study is going to calculate the area of West Java Province by using this method with several different number of partitions in each quadrant such as, 9 partitions, 11 partitions, and 36 partitions in for different quadrants. This study provides the final result of the approximate area which will be compared with the actual area based in the error of result. The main finding is the approximate total area will be closer to the actual area followed by the increasing number of partitions.
\end{abstract}

Keywords: Trapezoidal rule, numerical integration, area approximation

\section{Introduction}

Problems involving modeling are often found in various fields of science, especially mathematics, for example in food optimization modeling ( $\mathrm{Li}$ et al., 2019), statistical modeling (Fayyoumi et al., 2020; Carter et al., 2018) and computer science modeling (Medvedev, 2019; Austin et al., 2002; Sambas et al., 2021). One of the modeling in integral form is the determination of the area of a regular or irregular shape, it can also be used to determine the volume of a space.

One of the methods of mathematical modeling using integrals is the Trapezoidal Rule method, where this method uses the concept of integral to calculate the area under the curve in intervals (Wu and Smolinski, 2000; Zhang et al., 2010; Qiao et al., 2019). The Trapezoidal Rule method is included in the numerical method, which is a method for solving mathematical models with solving techniques that are formulated mathematically with basic arithmetic operations and are carried out repeatedly with the help of computers or manually, so that the results obtained are in the form of approximate values that produce errors. This numerical integral method can be used if the integral is difficult to solve analytically.

The Trapezoidal Rule Method has an important role in various disciplines, such as calculation of the area under the plasma level-time curve (Chiou, 1978), solution of the area under a curve calculation (Yeh, 2002), solving of the linear integro-differential equations (Saadati et al., 2008), solution of structural dynamics (Wu and Smolinski, 2000), solution of initial value problems (Gourlay, 1970), numerical solution of first order IVPs (Abbas, 2006) and solution of the transient Navier-Stokes equations (Feng et al., 2011).

This study will calculate the approximation area of West Java Province using the Trapezoidal Rule method with several types of partitions in four different quadrants. The purpose of this study is to calculate the approximation area of West Java Province and compare it with the latest actual area, which is $35,377.76 \mathrm{~km}^{2}$ (BPS West Java Province, 2021). 


\section{Materials and Methods}

\subsection{Numerical Integration}

In calculus, a definite integral is defined as the limit of the Riemann sum (Hairer et al., 2006),

$$
I(f)=\int_{a}^{b} f(x) d x
$$

and proves that,

$$
I(f)=F(b)-F(a)
$$

where $F(x)$ is the antiderivative of $f(x)$. Many integral forms can be evaluated using this formula. However, there are some integrals that cannot be evaluated by the equation (2) formula because the integrand $f(x)$ has no antiderivative so that other methods must be used to evaluate it.

\subsection{Trapezoidal Rule Method}

The main idea for approximation (Hairer et al., 2006),

$$
I(f)=\int_{a}^{b} f(x) d x
$$

is to replace $f(x)$ with an approximation function whose integral can be evaluated. Suppose $f(x)$ approximated by a linear polynomial,

$$
P_{1}(x)=\frac{(b-x) f(a)+(x-a) f(b)}{b-a}
$$

interpolating $f(x)$ on $a$ and $b$. Given if,

$$
T_{1}(f)=(b-a)\left[\frac{f(a)+f(b)}{2}\right]
$$

To improve the approximation $T_{1}(f)$ of equation (5) when $f(x)$ the function is not nearly linear on $[a, b]$, break the interval $[a, b]$ into smaller subintervals and apply equation (5) to each of the subintervals. If the subintervals are small enough, $f(x)$ will be almost linear in each of them. Suppose there are $n$ subintervals, then the following formula is obtained in equation (6):

$$
\begin{gathered}
T_{n}(f)=h\left[\frac{1}{2} f\left(x_{0}\right)+f\left(x_{1}\right)+f\left(x_{2}\right)+\cdots+f\left(x_{n-1}\right)\right. \\
\left.+\frac{1}{2} f\left(x_{n}\right)\right] .
\end{gathered}
$$

This formula is called the trapezoidal numerical integration rule. The subscript $n$ states the number of subintervals used, and the points $x_{0}, x_{1}, \ldots, x_{n}$ are called numerical integration vertices.

\subsection{Relative Error Formula}

To determine the level of accuracy of numerical integration using the Trapezoidal Rule method, it is necessary to find the relative error of the exact value with the formula:

$$
E=\frac{\text { Actual Area }- \text { Approximation Total Area }}{\text { Actual Area }} \times 100 \%
$$

So, with the above formula we can see the relative error percentage from a calculation result using the Trapezoidal Rule method. 


\section{Results and Discussion}

Discussion in this paper presents a direct application of West Java Province approximation area using the Trapezoidal Rule method. West Java is one of the large and developed provinces in Indonesia which has an area of $35,377.75 \mathrm{~km}^{2}$ (BPS West Java Province, 2021). The map of West Java is shown in Figure 1.

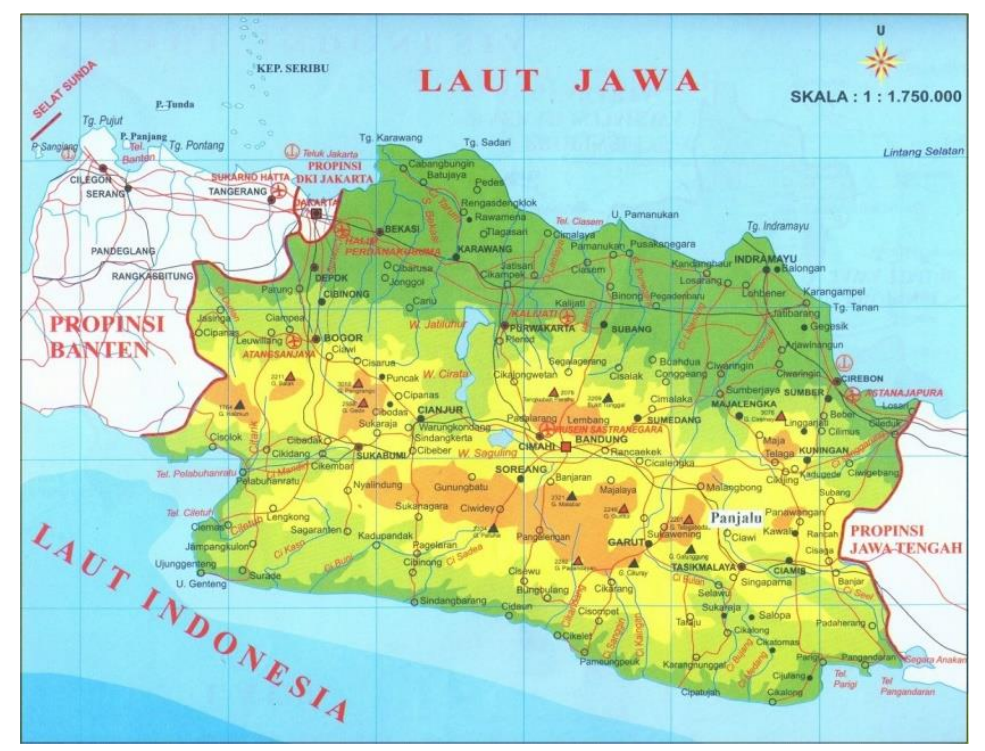

Figure 1: . Map of West Java Province in Indonesia

Because if West Java is projected onto the axis of symmetry in the form of an irregular area, the Trapezoidal Rule method can be applied with the help of dividing the area into four quadrants, where each quadrant is divided into various number of partitions.

\subsection{Region 1 Calculation With 9, 18, and 36 Partitions}

In region 1 (quadrant one) on the map of West Java, it is divided into 9 partitions as shown in Figure 2. It is assumed that the Bandung City is the center point or the center point of the coordinates $(0,0)$, so that the axis length $x$ for region one is $125.71 \mathrm{~km}$ with $h$ the amount 13.96 obtained from the division the length of the axis $x$ with the number of partitions is 9 . For 18 partitions, $h$ is 6.98 obtained from the division the length of the axis $x$ with the number of partitions is 18 . For 36 partitions, $h$ is 3.49 obtained from the division the length of the axis $x$ with the number of partitions is 36 .

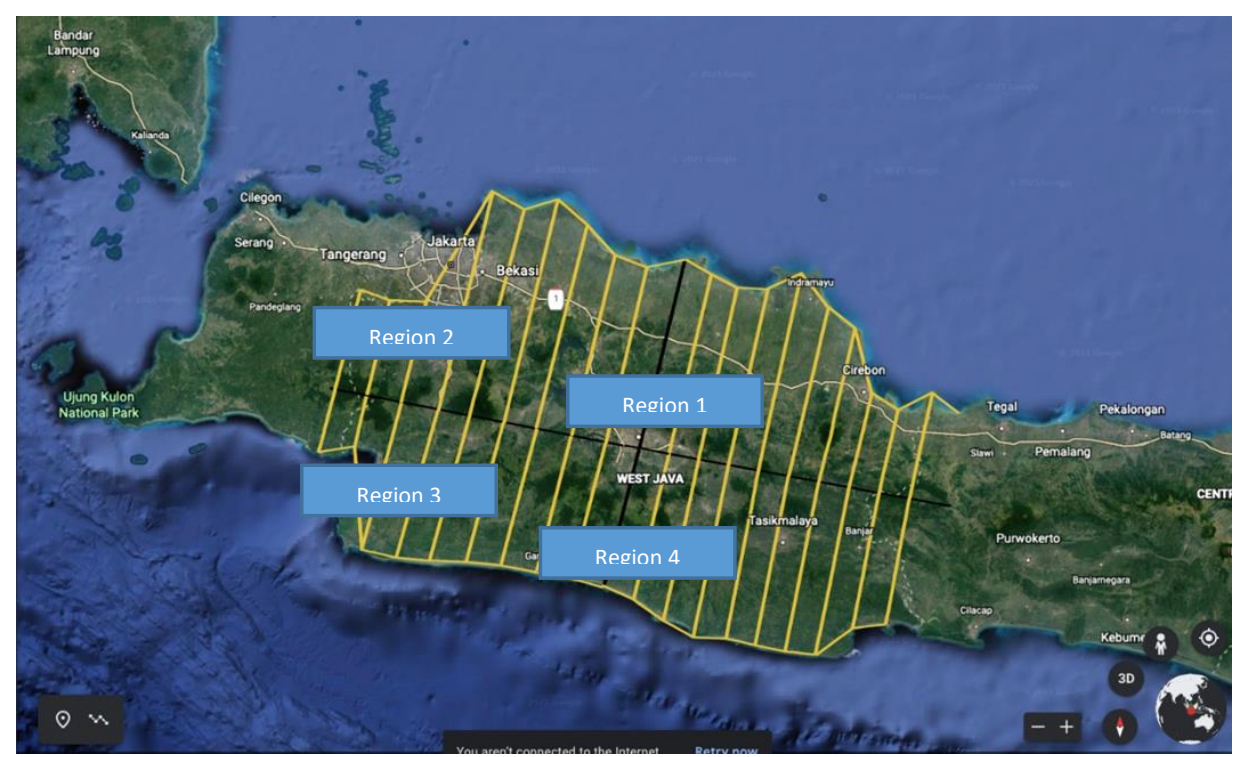

Figure 2. Division of West Java region with 9 partitions 
Table 1. Region 1 coordinats for 9,18 , and 36 partitions

\begin{tabular}{|c|c|c|c|}
\hline \multicolumn{4}{|c|}{ REGION 1} \\
\hline 9 Partitions & 18 Partitions & $36 \mathrm{P}$ & ions \\
\hline $\begin{array}{l}\left(x_{0}, y_{0}\right)=(0 ; 87,76) \\
\left(x_{1}, y_{1}\right)=(13.96 ; 83.7) \\
\left(x_{2}, y_{2}\right)=(27.93 ; 79.61) \\
\left(x_{3}, y_{3}\right)=(41.9 ; 82.09) \\
\left(x_{4}, y_{4}\right)=(55.87 ; 91.57) \\
\left(x_{5}, y_{5}\right)=(69.83 ; 79.15) \\
\left(x_{6}, y_{6}\right)=(86.592 ; 71.77) \\
\left(x_{7}, y_{7}\right)=(83.806 ; 44.16) \\
\left(x_{8}, y_{8}\right)=(97.77 ; 38.54) \\
\left(x_{9}, y_{9}\right)=(125.71 ; 48.76) \\
\underbrace{}_{\mathrm{A}}\end{array}$ & $\begin{array}{c}\mathrm{A} \\
\left(x_{1}, y_{1}\right)=(6.98 ; 85.81) \\
\left(x_{3}, y_{3}\right)=(20.94 ; 81.12) \\
\left(x_{5}, y_{5}\right)=(34.9 ; 78.21) \\
\left(x_{7}, y_{7}\right)=(48.86 ; 90.34) \\
\left(x_{9}, y_{9}\right)=(62.82 ; 94.3) \\
\left(x_{11}, y_{11}\right) \\
=(76.78 ; 73.68) \\
\left(x_{13}, y_{13}\right) \\
=(90.74 ; 56.13) \\
\left(x_{15}, y_{15}\right) \\
=(104.7 ; 41.86) \\
\left(x_{17}, y_{17}\right) \\
=(118.66 ; 39.07) \\
\mathrm{B}\end{array}$ & $\begin{array}{c}\left(x_{1}, y_{1}\right)=(3.49 ; 86.26) \\
\left(x_{3}, y_{3}\right)=(10.47 ; 84.21) \\
\left(x_{5}, y_{5}\right)=(17.45 ; 81.8) \\
\left(x_{7}, y_{7}\right)=(24.43 ; 80.58) \\
\left(x_{9}, y_{9}\right)=(31.41 ; 78.8) \\
\left(x_{11}, y_{11}\right)=(38.39 ; 79.01) \\
\left(x_{13}, y_{13}\right)=(45.37 ; 84.05) \\
\left(x_{15}, y_{15}\right)=(52.35 ; 90.95) \\
\left(x_{17}, y_{17}\right)=(59.33 ; 90.66) \\
\left(x_{19}, y_{9}\right)=(66.31 ; 82.29)\end{array}$ & $\begin{array}{c}\left(x_{21}, y_{21}\right)=(73.29 ; 76.1) \\
\left(x_{23}, y_{23}\right)=(80.27 ; 71.66) \\
\left(x_{25}, y_{25}\right)=(87.25 ; 66.94) \\
\left(x_{27}, y_{27}\right)=(94.23 ; 50.36) \\
\left(x_{29}, y_{29}\right)=(101.21 ; 41.43) \\
\left(x_{31}, y_{31}\right)=(108.19 ; 42.3) \\
\left(x_{33}, y_{33}\right)=(115.17 ; 38.66) \\
\left(x_{35}, y_{35}\right)=(122.15 ; 42.78) \\
\text { A } \\
\text { B }\end{array}$ \\
\hline
\end{tabular}

\subsection{Region 2 Calculation With 9, 18, and 36 Partitions}

In region 2 (quadrant two) on the map of West Java, it is divided into 9, 18, and 36 partitions. It is assumed that the city of Bandung is the center point or the center point of the coordinates $(0,0)$, so that the axis length $x$ for region two is $134.71 \mathrm{~km}$ with $h$ the amount 14.96 obtained from the division the length of the axis $x$ with the number of partitions is 9. For 18 partitions, $h$ is 7.48 obtained from the division the length of the axis $x$ with the number of partitions is 18 . For 36 partitions, $h$ is 3.74 obtained from the division the length of the axis $x$ with the number of partitions is 36 (See Table 2).

Table 2. Region 2 cordinats for 9,18 , and 36 partitions

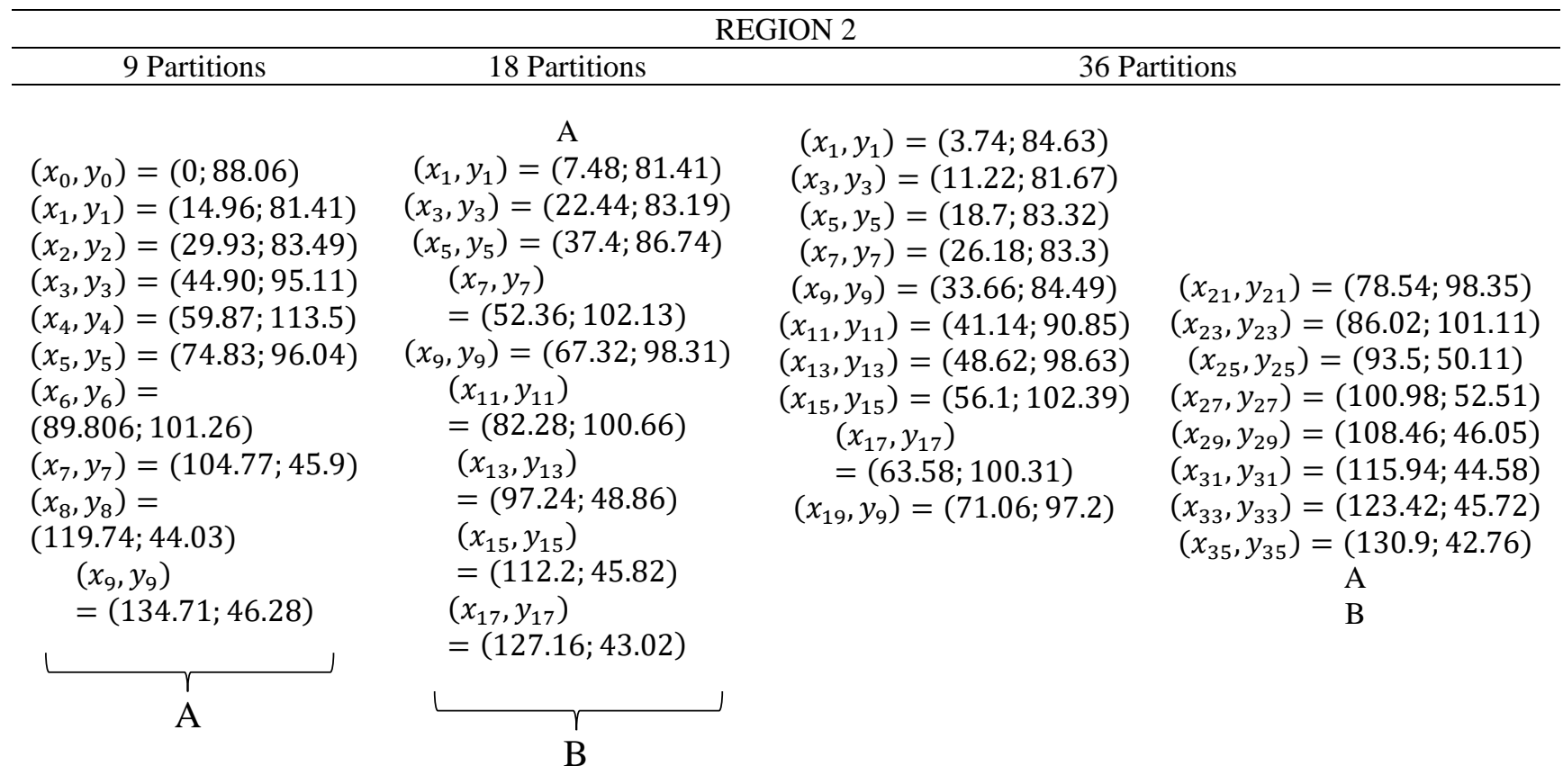


In region 3 (quadrant three) on the map of West Java, it is divided into 9, 18, and 36 partitions. It is assumed that the city of Bandung is the center point or the center point of the coordinates $(0,0)$, so that the axis length $x$ and the $h$ for 9,18 , and 36 partitions for region three is same with region two (See Table 3).

Table 3. Region 3 coordinats for 9,18 , and 36 partitions

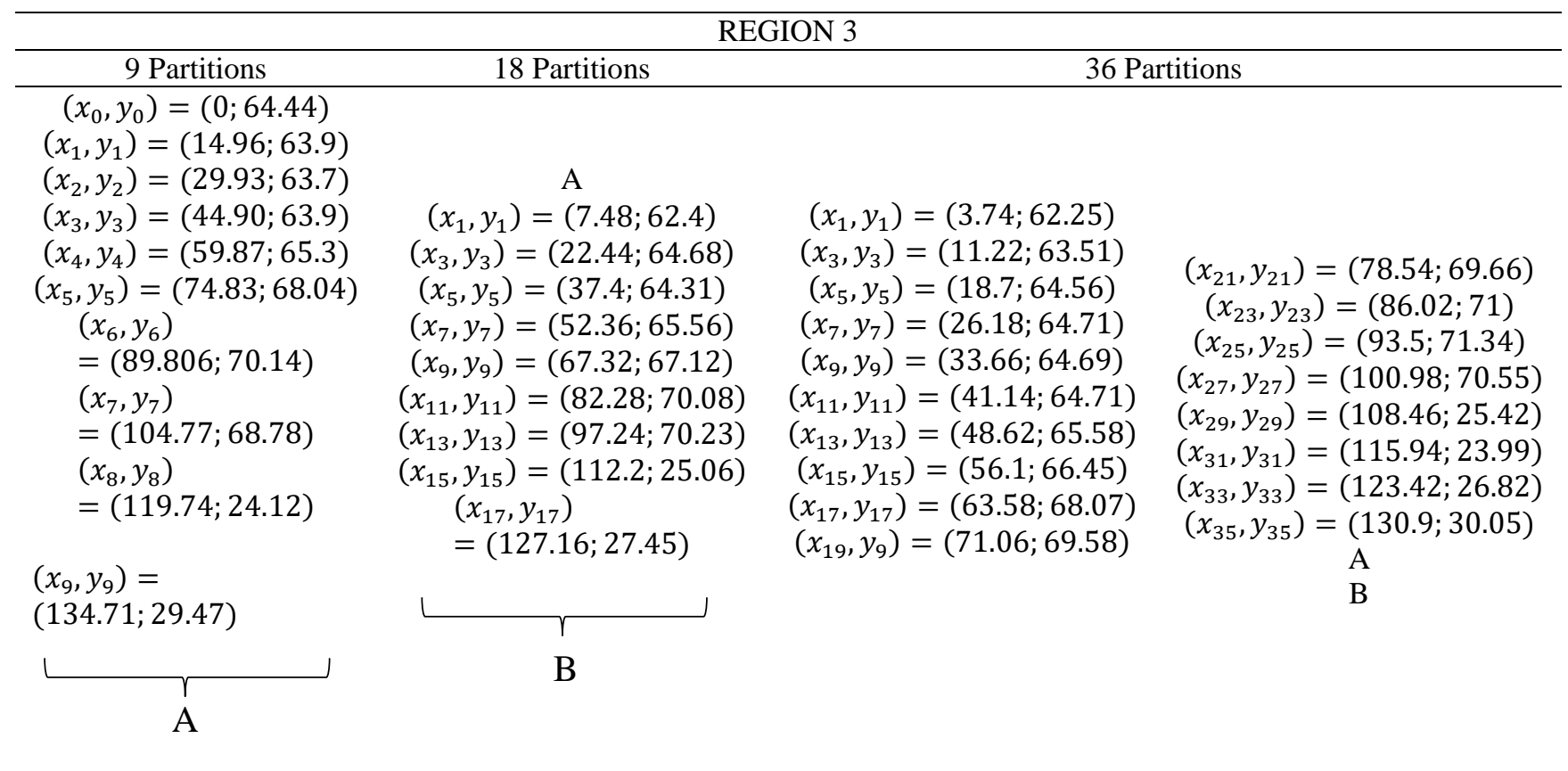

\subsection{Region 4 Calculation With 9, 18, and 36 Partitions}

In region 4 (quadrant four) on the map of West Java, it is divided into 9, 18, and 36 partitions. It is assumed that the city of Bandung is the center point or the center point of the coordinates $(0,0)$, so that the axis length $x$ and the $h$ for 9,18 , and 36 partitions for region three is same with region one (See Table 4).

Table 4. Region 4 coordinats for 9,18 , and 36 partitions

\begin{tabular}{|c|c|c|c|}
\hline \multicolumn{4}{|c|}{ REGION 4} \\
\hline 9 Partitions & 18 Partitions & 361 & titions \\
\hline $\begin{array}{c}\left(x_{1}, y_{1}\right)=(13.96 ; 66.38) \\
\left(x_{2}, y_{2}\right)=(27.93 ; 74.82) \\
\left(x_{3}, y_{3}\right)=(41.9 ; 79.19) \\
\left(x_{4}, y_{4}\right)=(55.87 ; 77.45) \\
\left(x_{5}, y_{5}\right)=(69.83 ; 78.44) \\
\left(x_{6}, y_{6}\right)=(86.592 ; 79.03) \\
\left(x_{7}, y_{7}\right)=(83.806 ; 77.27) \\
\left(x_{8}, y_{8}\right)=(97.77 ; 63.0) \\
\left(x_{9}, y_{9}\right)=(125.71 ; 58.16) \\
\underbrace{}_{\mathrm{A}}\end{array}$ & $\begin{array}{c}\left(x_{1}, y_{1}\right)=(6.98 ; 65.43) \\
\left(x_{3}, y_{3}\right)=(20.94 ; 70.65) \\
\left(x_{5}, y_{5}\right)=(34.9 ; 75.75) \\
\left(x_{7}, y_{7}\right)=(48.86 ; 78.74) \\
\left(x_{9}, y_{9}\right)=(62.82 ; 77.54) \\
\left(x_{11}, y_{11}\right)=(76.78 ; 78.01) \\
\left(x_{13}, y_{13}\right)=(90.74 ; 78.43) \\
\left(x_{15}, y_{15}\right)=(104.7 ; 76.69) \\
\left(x_{17}, y_{17}\right) \\
=(118.66 ; 58.81) \\
\mathrm{A}\end{array}$ & $\begin{array}{c}\left(x_{1}, y_{1}\right)=(3.49 ; 65.12) \\
\left(x_{3}, y_{3}\right)=(10.47 ; 65.76) \\
\left(x_{5}, y_{5}\right)=(17.45 ; 68.77) \\
\left(x_{7}, y_{7}\right)=(24.43 ; 72.77) \\
\left(x_{9}, y_{9}\right)=(31.41 ; 74.45) \\
\left(x_{11}, y_{11}\right)=(38.39 ; 75.47) \\
\left(x_{13}, y_{13}\right)=(45.37 ; 79.91) \\
\left(x_{15}, y_{15}\right)=(52.35 ; 77.53) \\
\left(x_{17}, y_{17}\right)=(59.33 ; 77.81) \\
\left(x_{19}, y_{9}\right)=(66.31 ; 78.08)\end{array}$ & $\begin{array}{c}\left(x_{21}, y_{21}\right)=(73.29 ; 79.08) \\
\left(x_{23}, y_{23}\right)=(80.27 ; 78.78) \\
\left(x_{25}, y_{25}\right)=(87.25 ; 79.09) \\
\left(x_{27}, y_{27}\right)=(94.23 ; 78.79) \\
\left(x_{29}, y_{29}\right)=(101.21 ; 77.57) \\
\left(x_{31}, y_{31}\right)=(108.19 ; 76.44) \\
\left(x_{33}, y_{33}\right)=(115.17 ; 60.4) \\
\left(x_{35}, y_{35}\right)=(122.15 ; 58.38)\end{array}$ \\
\hline
\end{tabular}




\subsection{Area Calculation}

\subsubsection{Total Area for 9 Partitions}

It is known that the number of intervals is $n=9$, so the calculation of area 1 using the Trapezoidal Rule method is as follows:

$$
\begin{aligned}
T_{9}(f) & =h\left[\frac{1}{2} f\left(x_{0}\right)+f\left(x_{1}\right)+f\left(x_{2}\right)+\cdots+f\left(x_{8}\right)+\frac{1}{2} f\left(x_{9}\right)\right], \\
T_{9}(f) & =10.773\left[\frac{1}{2}(87.76)+83.7+79.61+82.09+91.57+79.15+71.77+44.16++38.54+\frac{1}{2}(48.76)\right] \\
& =8.923,315 \mathrm{~km}^{2} .
\end{aligned}
$$

The calculation of area 2 is as follows:

$$
\begin{aligned}
T_{9}(f) & =h\left[\frac{1}{2} f\left(x_{0}\right)+f\left(x_{1}\right)+f\left(x_{2}\right)+\cdots+f\left(x_{8}\right)+\frac{1}{2} f\left(x_{9}\right)\right], \\
T_{9}(f) & =10.773\left[\frac{1}{2}(88.08)+81.41+83.49+95.11+113.5+96.04+101.26+45.9+44.03+\frac{1}{2}(46.28)\right] \\
& =10.895,34 \mathrm{~km}^{2} .
\end{aligned}
$$

The calculation of area 3 is as follows:

$$
\begin{aligned}
T_{9}(f) & =h\left[\frac{1}{2} f\left(x_{0}\right)+f\left(x_{1}\right)+f\left(x_{2}\right)+\cdots+f\left(x_{8}\right)+\frac{1}{2} f\left(x_{9}\right)\right], \\
T_{9}(f) & =10.773\left[\frac{1}{2}(64.44)+63.9+63.7+63.9+65.3+68.04+70.14+68.78+24.12+\frac{1}{2}(29.47)\right] \\
& =8.005,291 \mathrm{~km}^{2} .
\end{aligned}
$$

The calculation of area 4 is as follows:

$$
\begin{aligned}
T_{9}(f) & =h\left[\frac{1}{2} f\left(x_{0}\right)+f\left(x_{1}\right)+f\left(x_{2}\right)+\cdots+f\left(x_{8}\right)+\frac{1}{2} f\left(x_{9}\right)\right], \\
T_{9}(f) & =10.773\left[\frac{1}{2}(64.58)+66.38+74.82+79.19+77.45+78.44+79.03+77.27+63.9+\frac{1}{2}(58.16)\right] \\
& =9.188,703 \mathrm{~km}^{2} .
\end{aligned}
$$

\subsubsection{Total Area for 18 Partitions}

It is known that the number of intervals is $n=18$, so the calculation of area 1 using the Trapezoidal Rule method is as follows:

$$
\begin{aligned}
& T_{9}(f)=h\left[\frac{1}{2} f\left(x_{0}\right)+f\left(x_{1}\right)+f\left(x_{2}\right)+\cdots+f\left(x_{17}\right)+\frac{1}{2} f\left(x_{18}\right)\right], \\
& T_{18}(f)=6.98\left[\frac{1}{2}(87.76)+(85.81)+(82.96)+\cdots+(38.74)+(39.07)+\frac{1}{2}(48.37)\right]=8.909,42 \mathrm{~km}^{2} .
\end{aligned}
$$

The calculation of area 2 is as follows:

$$
\begin{aligned}
& T_{18}(f)=h\left[\frac{1}{2} f\left(x_{0}\right)+f\left(x_{1}\right)+f\left(x_{2}\right)+\cdots+f\left(x_{17}\right)+\frac{1}{2} f\left(x_{18}\right)\right], \\
& T_{18}(f)=7.48\left[\frac{1}{2}(87.76)+(81.41)+(81.15)+\cdots+(43.89)+(43.02)+\frac{1}{2}(45.7)\right]=10.545,77 \mathrm{~km}^{2} .
\end{aligned}
$$

The calculation of area 3 is as follows:

$$
\begin{aligned}
T_{9}(f) & =h\left[\frac{1}{2} f\left(x_{0}\right)+f\left(x_{1}\right)+f\left(x_{2}\right)+\cdots+f\left(x_{17}\right)+\frac{1}{2} f\left(x_{18}\right)\right], \\
T_{18}(f) & =7.48\left[\frac{1}{2}(64.58)+(62.4)+(63.46)+\cdots+(23.82)+(27.45)+\frac{1}{2}(29.1)\right]=7.877,766 \mathrm{~km}^{2} .
\end{aligned}
$$

The calculation of area 4 is as follows:

$$
\begin{aligned}
& T_{18}(f)=h\left[\frac{1}{2} f\left(x_{0}\right)+f\left(x_{1}\right)+f\left(x_{2}\right)+\cdots+f\left(x_{17}\right)+\frac{1}{2} f\left(x_{18}\right)\right], \\
& T_{18}(f)=6.98\left[\frac{1}{2}(64.58)+(65.43)+(67.86)+\cdots+(73.2)+(58.81)+\frac{1}{2}(58.57)\right]=9.288,048 \mathrm{~km}^{2} .
\end{aligned}
$$




\subsubsection{Total Area for 36 Partitions}

It is known that the number of intervals is $n=36$, so the calculation of area 1 using the Trapezoidal Rule method is as follows:

$$
\begin{aligned}
& T_{36}(f)=h\left[\frac{1}{2} f\left(x_{0}\right)+f\left(x_{1}\right)+f\left(x_{2}\right)+\cdots+f\left(x_{17}\right)+\frac{1}{2} f\left(x_{36}\right)\right], \\
& T_{36}(f)=3.49\left[\frac{1}{2}(87.76)+(86.26)+(85.62)+\cdots+(38.76)+(42.78)+\frac{1}{2}(48.53)\right]=8.883,35 \mathrm{~km}^{2} .
\end{aligned}
$$

Calculation of area 2 is as follows:

$$
\begin{aligned}
& T_{36}(f)=h\left[\frac{1}{2} f\left(x_{0}\right)+f\left(x_{1}\right)+f\left(x_{2}\right)+\cdots+f\left(x_{17}\right)+\frac{1}{2} f\left(x_{36}\right)\right], \\
& T_{36}(f)=3.74\left[\frac{1}{2}(87.76)+(84.63)+(81.21)+\cdots+(43.32)+(42.76)+\frac{1}{2}(46.93)\right]=10.473,72 \mathrm{~km}^{2} .
\end{aligned}
$$

Calculation of area 3 is as follows:

$$
\begin{aligned}
& T_{36}(f)=h\left[\frac{1}{2} f\left(x_{0}\right)+f\left(x_{1}\right)+f\left(x_{2}\right)+\cdots+f\left(x_{17}\right)+\frac{1}{2} f\left(x_{36}\right)\right], \\
& T_{36}(f)=3.49\left[\frac{1}{2}(64.58)+(62.97)+(63.51)+\cdots+(27.04)+(30.05)+\frac{1}{2}(30.09)\right]=7.852,078 \mathrm{~km}^{2} .
\end{aligned}
$$

Calculation of area 4 is as follows:

$$
\begin{aligned}
& T_{36}(f)=h\left[\frac{1}{2} f\left(x_{0}\right)+f\left(x_{1}\right)+f\left(x_{2}\right)+\cdots+f\left(x_{17}\right)+\frac{1}{2} f\left(x_{36}\right)\right], \\
& T_{36}(f)=3.74\left[\frac{1}{2}(64.58)+(65.12)+(65.47)+\cdots+(59.66)+(58.38)+\frac{1}{2}(58.88)\right]=9.2711,811 \mathrm{~km}^{2} .
\end{aligned}
$$

\subsection{Calculation Area of the Province West Java}

Based on the calculation of the area of the province of West Java using the Trapezoidal Rule method with 9, 18, and 36 partitions in each quadrant, the results are shown in Table 4. Based on Table 4, it can be seen that the approximate total area will be closer to the actual area followed by the increasing number of partitions.

Table 4. Total area comparison

\begin{tabular}{cccc}
\hline & 9 PARTITIONS & 18 PARTITIONS & 36 PARTITIONS \\
\hline REGION 1 $\left(\mathrm{km}^{2}\right)$ & $10,570.33$ & $8,923.315$ & $8,909.242$ \\
REGION 2 $\left(\mathrm{km}^{2}\right)$ & $12,543.39$ & $10,895.34$ & $10,545.77$ \\
REGION 3 $\left(\mathrm{km}^{2}\right)$ & $8,703.344$ & $8,005.291$ & $7,877.766$ \\
REGION 4 $\left(\mathrm{km}^{2}\right)$ & $9,286.198$ & $9,188.703$ & $9,288.048$ \\
TOTAL AREA $\left(\mathrm{km}^{2}\right)$ & $41,103.262$ & $37,012.649$ & $36,620.826$ \\
ACTUAL AREA $\left(\mathrm{km}^{2}\right)$ & $35,377.76$ & $35,377.76$ & $35,377.76$ \\
ERROR & $13.92 \%$ & $4.62 \%$ & $3.51 \%$ \\
\hline
\end{tabular}

\section{Conclussion}

In this paper, we have studied area of West Java Province by using this method with several different number of partitions in each quadrant such as, 9 partitions, 11 partitions, and 36 partitions in for different quadrants. The main finding is the approximate total area will be closer to the actual area followed by the increasing number of partitions. For further research, we will compare performance of trapezoidal rule method with other method.

\section{References}

Abbas, S. (2006). Derivation of a new block method similar to the block trapezoidal rule for the numerical solution of first order IVPs. Science Echoes, 2, 10-24.

Austin, T., Larson, E., \& Ernst, D. (2002). SimpleScalar: An infrastructure for computer system modeling. Computer, 35(2), 5967.

Carter, D. J., Glaziou, P., Lönnroth, K., Siroka, A., Floyd, K., Weil, D., \& Boccia, D. (2018). The impact of social protection and poverty elimination on global tuberculosis incidence: a statistical modelling analysis of Sustainable Development Goal 1. The Lancet Global Health, 6(5), e514-e522. 
Chiou, W. L. (1978). Critical evaluation of the potential error in pharmacokinetic studies of using the linear trapezoidal rule method for the calculation of the area under the plasma level-time curve. Journal of pharmacokinetics and biopharmaceutics, 6(6), 539-546.

Fayyoumi, E., Idwan, S., \& AboShindi, H. (2020). Machine learning and statistical modelling for prediction of novel covid-19 patients case study: Jordan. Machine Learning, 11(5), 3-11.

Feng, M., Bai, Y., He, Y., \& Qin, Y. (2011). A new stabilized subgrid eddy viscosity method based on pressure projection and extrapolated trapezoidal rule for the transient Navier-Stokes equations. Journal of Computational Mathematics, 29(4), 415440.

Gourlay, A. R. (1970). A note on trapezoidal methods for the solution of initial value problems. Mathematics of Computation, 24(111), 629-633.

Hairer, E., Hochbruck, M., Iserles, A., \& Lubich, C. (2006). Geometric numerical integration. Oberwolfach Reports, 3(1), 805882.

Li, M., Fu, Q., Singh, V. P., Liu, D., \& Li, T. (2019). Stochastic multi-objective modeling for optimization of water-food-energy nexus of irrigated agriculture. Advances in water resources, 127, 209-224.

Medvedev, P. (2019). Modeling biological problems in computer science: a case study in genome assembly. Briefings in bioinformatics, 20(4), 1376-1383.

Qiao, L., Xu, D., \& Wang, Z. (2019). An ADI difference scheme based on fractional trapezoidal rule for fractional integrodifferential equation with a weakly singular kernel. Applied Mathematics and Computation, 354, $103-114$.

Saadati, R., Raftari, B., Abibi, H., Vaezpour, S. M., \& Shakeri, S. (2008). A comparison between the Variational Iteration method and Trapezoidal rule for solving linear integro-differential equations. World Applied Sciences Journal, 4(3), 321-325.

Sambas, A., Vaidyanathan, S., Bonny, T., Zhang, S., Hidayat, Y., Gundara, G., \& Mamat, M. (2021). Mathematical Model and FPGA Realization of a Multi-Stable Chaotic Dynamical System with a Closed Butterfly-Like Curve of Equilibrium Points. Applied Sciences, 11(2), 788.

Wu, Y. S., \& Smolinski, P. (2000). A multi-time step integration algorithm for structural dynamics based on the modified trapezoidal rule. Computer Methods in Applied Mechanics and Engineering, 187(3-4), 641-660.

Yeh, S. T. (2002). Using trapezoidal rule for the area under a curve calculation. Proceedings of the 27th Annual SAS® User Group International (SUGI'02), 1-5.

Zhang, X., Wu, J., \& Yu, D. (2010). The superconvergence of composite trapezoidal rule for Hadamard finite-part integral on a circle and its application. International Journal of Computer Mathematics, 87(4), 855-876. 